\title{
Ten years of Arabian oryx conservation breeding in Saudi Arabia - achievements and regional perspectives
}

\author{
Stéphane Ostrowski, Eric Bedin, Daniel M. Lenain and \\ Abdulaziz H. Abuzinada
}

\begin{abstract}
The National Commission for Wildlife Conservation and Development was established in 1986 to oversee all wildlife conservation programmes in Saudi Arabia. The Arabian oryx Oryx leucoryx is one of the flagship species of the Saudi Arabian reintroduction policy. It has been captive-bred since 1986 at the National Wildlife Research Center near Taif. With the creation of a network of protected areas in the former distribution range of the species, attention has shifted to the release of captive-bred oryx into Mahazat as-Sayd and 'Uruq Bani Ma'arid reserves. Similar programmes carried out in other countries of the Arabian Peninsula underline the need for regional co-operation and pan-Arabic public awareness programmes, in addition to captive-breeding and reintroduction projects.
\end{abstract}

\section{Introduction}

The Arabian oryx Oryx leucoryx is a charismatic animal; merely the beauty of its eyes was enough to inspire the poets of the Arab world. Unfortunately, this beauty did not confer immortality, and over hundreds of years the Arabian oryx was pursued and hunted in its most remote desert strongholds. The last wild Arabian oryx was probably killed in 1972 (Henderson, 1974), and its death became a symbol of human destruction of the natural world. Humans exterminated from the wild a beautiful and distinctive antelope, which had evolved to exploit one of the world's harshest environments. The capture of a few of the last wild oryx in 1962 (Grimwood, 1962) marked the beginning of Operation Oryx. Through captive breeding, the return of descendants from the founder herd to Arabian lands was possible and oryx were first returned to the wild in Oman in 1982. With the release of oryx into the unfenced 'Uruq Bani Ma'arid protected area, the restoration of the Arabian oryx to the deserts of Saudi Arabia became a reality (Ancrenaz and Flamand, 1995). The reintroduction of Arabian oryx into Saudi Arabia (C) $1998 \mathrm{FFI}$, Oryx, $32(3), 209-222$ appears to be on the way to becoming another conservation success story.

The restoration of the Arabian oryx in Saudi Arabia is a core programme of the National Commission for Wildlife Conservation and Development (NCWCD), and has support at the highest governmental levels. Concurrent projects for the protection of large areas within the former range of the Arabian oryx, and the captive breeding of oryx at the National Wildlife Research Center (NWRC) have together enabled the restoration of the species in Saudi Arabia.

With releases into the wild, attention has shifted from the captive-breeding stock to the free-ranging Mahazat as-Sayd and 'Uruq Bani Ma'arid oryx populations. National endorsement of the latest release project in 'Uruq Bani $\mathrm{Ma}^{\prime}$ arid has encouraged further national efforts and new reintroductions are planned.

\section{Historical range}

Oryx once ranged throughout most of the desert plains of the Arabian Peninsula. Most recorded sightings come from the journals of 
the first European travellers to the region (e.g. Carruthers, 1935). Regions in Saudi Arabia known to have once held oryx include the Great Nafud Desert, the Rub'al-Khali and the sandy area known as the Dahana, which links these two deserts (Doughty, 1888; Carruthers, 1935; Raswan, 1935; Talbot, 1960). Elsewhere in the Arabian Peninsula, evidence of oryx has been found in the west of the United Arab Emirates, at the edges of Dhofar mountains, Rub'al-Khali and Jiddat al-Harasis regions of Oman, and in Yemen (Philby, 1933; Thesiger, 1948; Shepherd, 1965; Harrison and Bates, 1991). Even today horns and bones of oryx can still be found in the Rub'al-Khali's gravel plains. The former range of the species consisted of vast deserts, which were linked by gravel corridors and plains over which the animals were able to range for hundreds of kilometres (Harrison and Bates, 1991). In Iraq, the last oryx was shot in 1914 (Hatt, 1959), whereas oryx were still observed in Syria after the first World War (Harrison and Bates, 1991). Unconfirmed reports around this time of the presence of oryx in the volcanic plains of Harrat al-Harrah, north of the Nafud desert, could attest to a migration in response to human pressure. With the flow of oil revenue to Saudi Arabia in the second half of the century, pressures on oryx populations increased dramatically as they were heavily persecuted for trophies and for meat by hunters bearing automatic weapons and travelling in motorized fleets (Thesiger, 1948). By 1968, oryx range was limited to the southern and south-eastern borders of the Rub'al-Khali and the desert edge of Oman (Harrison and Bates, 1991). The last oryx were recorded alive in the wild in 1972 in Oman where they were killed or captured only a few weeks later (Henderson, 1974). Despite unconfirmed reports of a pair of oryx and a lone animal in 1978 and 1979 in the Rub'al-Khali, it is widely assumed that the Arabian oryx had been eradicated from the wild by the mid-1970s.

In the years before the last animals were shot, a number of individuals had been taken from the wild and kept in captivity within private collections throughout the Middle East. Capture of oryx from the wild in the Aden
Protectorate ('Operation Oryx'), followed by donations from some of these private collections, led to the formation of what is known as the World Herd (Grimwood, 1988).

\section{Saudi Arabia's Arabian oryx restoration programme}

\section{Conservation framework for the Arabian oryx}

The basis of Saudi Arabian conservation programmes for the Arabian oryx and other endangered species is the NCWCD's Protected Area System Plan (Child and Grainger, 1990). This document details the status of areas of interest for threatened taxa protection and describes the physiogeography of and management objectives for these areas. Additionally, a conservation strategy for the Arabian oryx (Seddon et al., 1996) is currently under review. The ultimate goal of the Saudi Arabian programme is to re-establish self-sustaining, freeranging populations of Arabian oryx within a framework of protected areas throughout the historically documented range of the species. Five phases have been defined towards the achievement of this goal.

1 To create and maintain an Arabian oryx captive-breeding facility at NWRC, and to develop techniques for the release of captivebred animals.

2 To create a network of protected areas within the historically documented range of the Arabian oryx in Saudi Arabia.

3 To supply these areas with the appropriate facilities and adequate personnel to support reintroduction operations.

4 To translocate oryx from captive-breeding facilities to suitably prepared protected areas. 5 To reinforce released populations until natural population growth appears sufficient to ensure self-sustainability.

Some of the protected areas are very close to the Kingdom's borders, so these management objectives call for regional co-operation with other organizations and countries with similar objectives. As in most reintroduction/re-establishment projects, promotion of public awareness campaigns and encouragement of 
Figure 1. Development of three captive-bred oryx populations (A, B, C) at the National Wildlife Research Center of Taif since 1986. A-generation oryx, animals imported to the NWRC, Taif; Bgeneration ory $x$, hand-reared animals (descendants of Ageneration animals); $C$ generation, mother-reared animals (descendants of Bgeneration animals).

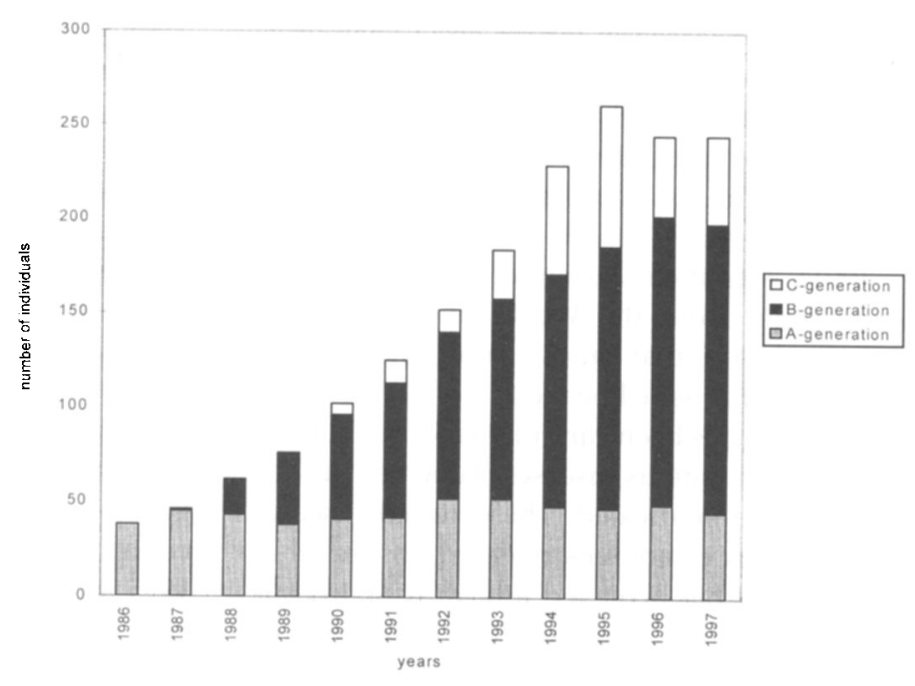

public support for Arabian oryx conservation are essential.

\section{Conservation breeding}

History. Deliberate and organized captive breeding of the Arabian oryx began in the Kingdom of Saudi Arabia in April 1986, when 57 animals were transported from the farm of the late King Khaled in Thumamah to the NWRC in Taif. During the first 2 months the mortality rate was high in the NWRC herd (Haagsma and Poilane, 1989). By September 1989, 16 (28 per cent) animals had died of tuberculosis. Because of the inestimable genetic value of the herd in relation to the rest of the world herd, it was decided to attempt to eradicate the infection through the use of sanitary and management measures (Flamand et al., 1994; Greth et al., 1994). The outbreak was brought under control, and efforts were directed toward rapid growth of the captive population in conjunction with genetic research and management (Greth and Schwede, 1993).

General management. Due to the tuberculosis outbreak shortly after the arrival of animals from Thumamah, individuals of the founder population, called the A generation, were kept in isolation to avoid the intraspecific risk of transmission of the disease. The second generation (B) comprises hand-reared animals whose mother-reared offspring ( $\mathrm{C}$ generation) are used for reintroduction. Drastic sanitary measures, antibiotic treatment, annual tuberculosis testing of all the captive animals and hand-rearing of calves from the founder generation enabled the breeding of tuberculosisfree animals. This 'three-generation management' has been maintained for basic sanitary purposes even after the captive herd was free of tuberculosis. On 1 January 1997, the NWRC herd numbered 49 A-generation, $151 \mathrm{~B}$-generation and $45 \mathrm{C}$-generation individuals (Figure 1).

Original aspects of the NWRC herd. The Arabian oryx is reared in captivity world-wide, with approximately 1600 animals in zoological or private collections in 1992 (Dolan and Sausman, 1992). The NWRC herd has the characteristics listed below.

- On 1 January 1997, 50 per cent of the captive population was less than 4 years old.

- Most individuals are young animals that have been born in captivity but reared with minimal contact with human beings.

- The NWRC oryx have the greatest genetic diversity of all captive and wild herds. 
Animals released in Jordan and Oman originated mainly from the American captive population, which was derived directly from the World Herd. Animals forming the breeding nucleus of the NWRC herd represent a wider genetic base (Vassart et al., 1991), with the inclusion of animals derived not only from the World Herd, but also from the original Saudi, Qatari (5) and Abu Dhabi (2) genetic lineages.

- The herd has been carefully screened for potential contagious diseases. Tuberculosis has now been eradicated. The certified diseasefree status of animals released ensures that this stock has achieved a healthy status superior to that of many other collections of animals, most of which lack the testing history designed to exclude tuberculosis.

- The NWRC oryx programme is capable of providing suitable animals for large-scale releases throughout Saudi Arabia.

\section{Reintroduction}

Oryx releases in Oman have been successfully carried out since 1982 (Stanley Price, 1989). The first oryx to return to Oman were zoobred. The project was a testing ground for the ability of the animals, several generations removed from the wild, to adapt and to thrive in their ancestral habitat. Fortunately for zoos and for conservation, the oryx generally acquitted themselves very well.

Mahazat as-Sayd reintroduction. The first area chosen for oryx releases in Saudi Arabia was the 2244-sq-km Mahazat as-Sayd protected area, $160 \mathrm{~km}$ north-east of Taif (Figure 2). Oral tradition and early written records indicate that this area was within the former range of the Arabian oryx. In 1989 the entire reserve was fenced to exclude poachers and grazing livestock. Mahazat as-Sayd is also a reintroduction site for the houbara bustard Chlamydotis undulata macqueenii (Seddon et al., 1995) and sand gazelle Gazella subgutturosa marica (Nayerul Haque and Smith, 1995), and an introduction site for the red-necked ostrich Struthio camelus camelus (Smith and Nayerul Haque, 1994).
Since 1990, 38 Arabian oryx from foreign, private or national collections (Table 1) and over 34 oryx from the captive-breeding unit at the NWRC have been taken to the reserve, held within a 200-ha enclosure, then released into the wider reserve. The genetic make-up of the population was enhanced by selecting a genetically diverse, initial founder herd. During 1990-92, a team of rangers under the supervision of the reserve's manager tracked and located oryx daily. As the population grew and animals dispersed into many small groups it became increasingly difficult to account for all of the oryx each day. Since May 1995 a monthly transect census has been carried out in the reserve, and by January 1998 , the population was estimated to be 350 individuals (Figure 3 ).

All reintroduced animals adapted quickly to their new environment without supplemental food or water. Although very degraded by livestock before fencing, rapid recovery of vegetation within the reserve helped to establish the reintroduced ungulate populations. The wild herd has demonstrated its potential for rapid increase in size with a high percentage of young-age classes. In addition to monitoring population dynamics, studies on the behavioural ecology and reproductive physiology of the animals are under way. A simulation model based on observed rates of productivity and survival indicates that the population will continue to grow at an increasing rate for the next few years, reaching 500 individuals by the year 2000 .

'Uruq Bani Ma'arid reintroduction. The 'Uruq Bani Ma'arid protected area covers approximately $12,000 \mathrm{sq} \mathrm{km}$ at the western edge of the Rub'al-Khali, or 'Empty Quarter' (Figure 2). The Tuwaiq ar'Ubm escarpment, rising $200-300 \mathrm{~m}$ above the plain, constitutes the western edge of the reserve. Ungulates vanished from the area as a result of over-hunting. According to local people, oryx and sand gazelles were seen at the edge of the top of the escarpment as recently as 35 years ago. This is probably due to the relatively good vegetation found in the wadis at the escarpment edge. The reserve has been divided into three 

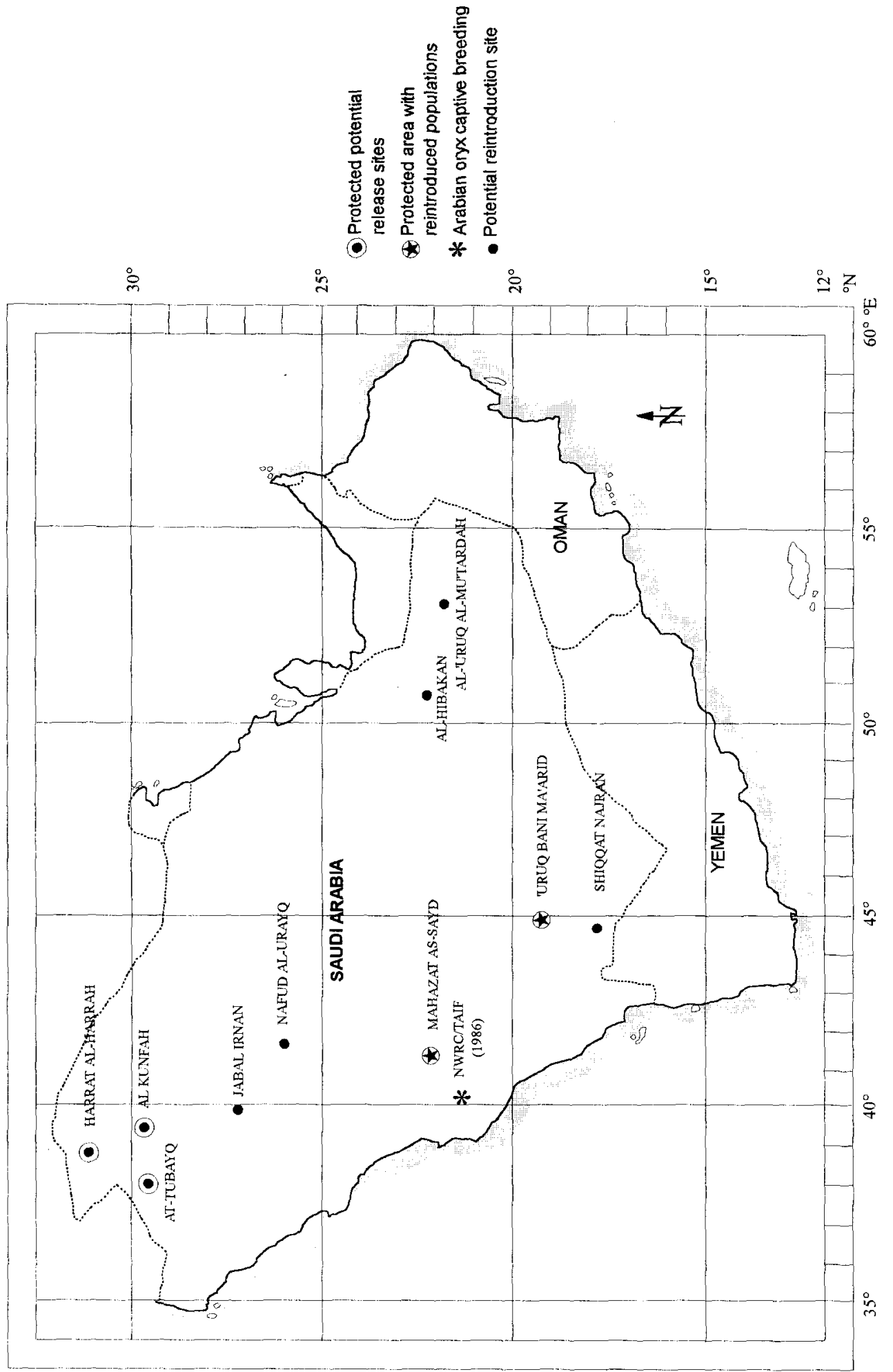

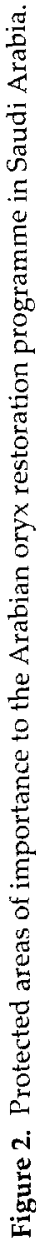




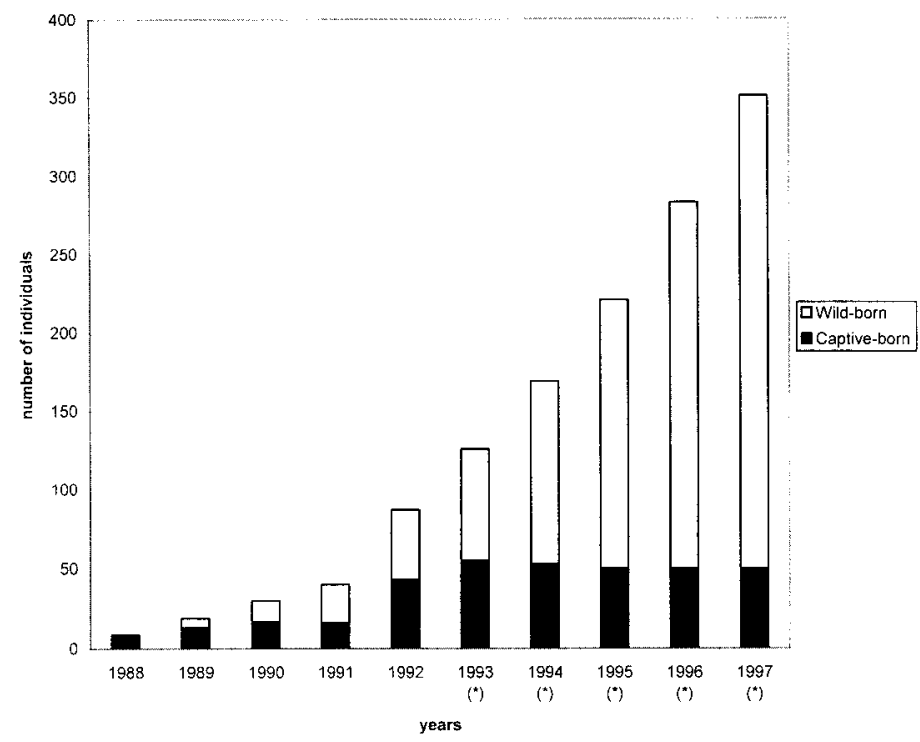

Figure 3. Population estimates of captive-born and wild-born Arabian oryx in Mahazat asSayd protected area since 1988. (*) Estimates since 1993.

Table 1. Origin of the captive-bred Arabian oryx brought to Mahazat as-Sayd Protected Area

\begin{tabular}{rlll}
\hline Date of arrival & $\begin{array}{l}\text { Number and } \\
\text { sex ratio }\end{array}$ & Origin & Blood lineage \\
\hline 30.11 .1988 & $9(5.4)$ & San Diego Zoo, USA & WH \\
20.03 .1989 & $8(4.4)$ & Shaumari reserve, Jordan & WH and Qatari \\
18.05 .1990 & $6(3.3)$ & San Diego Zoo, USA & WH \\
18.06 .1990 & $2(1.1)$ & Al-Areen collection, Bahrain & Abu Dhabit and Qatari \\
& $1(1.0)$ & Shahanyah collection, Qatar & Qatarif \\
06.05 .1991 & $1(1.0)$ & NWRC Taif, Saudi Arabia & Arabian $\S$ and WH \\
12.05 .1991 & $1(0.1)$ & NWRC Taif, Saudi Arabia & Arabian and WH \\
$8-15.01 .1992$ & $10(5.5)$ & NWRC Taif, Saudi Arabia & Arabian and WH \\
10.02 .1992 & $9(3.6)$ & San Diego Zoo, USA & WH \\
$17-24.11 .1992$ & $10(4.6)$ & NWRC Taif, Saudi Arabia & Arabian and WH \\
13.09 .1993 & $5(2.3)$ & NWRC Taif, Saudi Arabia & Arabian and WH \\
10.10 .1993 & $7(2.5)$ & NWRC Taif, Saudi Arabia & Arabian and WH \\
07.12 .1993 & $2(0.2)$ & Zurich Zoo, Switzerland & WH \\
22.12 .1993 & $1(1.0)$ & Berlin Tierpark, Germany & WH \\
\hline
\end{tabular}

* WH: World Herd comprised 3 (2.1) wild-caught animals in Aden Protectorate in May 1962, 1 (0.1) wildcaught animal offered by London Zoo in May 1963, 1 (0.1) wild-caught animal offered by HH Sheikh Abdullah al Sabah, ruler of Kuwait, 4 (2.2) animals offered by HM King Saud of Saudi Arabia in March 1964 (Homan, 1988), and 2 (1.1) animals bought from Riyadh Zoo in 1967.

+ Abu Dhabi: Originated from the Sheik Zahid bin Sultan al-Nahyana ruler of Abu Dhabi collection (J. Samour, pers.comm.).

₹Qatari: Originated from wild-caught animals from the southern Rub'al-Khali in Saudi Arabia and western Oman in the late 1950s and early 1960 s (Jones, 1988).

$\S$ Arabian: Originated from HM King Khaled's collection at Thumamah, composed of Saudi animals, WH and probably some Riyadh Zoo, Qatar and Al-Areen lineages (Abuzinada et al., 1988; Asmodé and Khoja, 1988; Vassart et al., 1991). 
different zones. Hunting is forbidden in two of them and controlled in the third one.

- A 'Special Nature Reserve' or core area of approximately $2000 \mathrm{sq} \mathrm{km}$, which includes the escarpment and the western edge of the dune system. Human settlements, human activities and domestic livestock are forbidden in this area.

- A 'Resource Use Reserve' surrounds the core area and covers approximately $5000 \mathrm{sq}$ $\mathrm{km}$. Use by local inhabitants and their livestock is regulated by wildlife rangers.

- A 'Controlled Hunting Reserve' surrounds the two previous areas and covers approximately $5000 \mathrm{sq} \mathrm{km}$. Human activities, apart from hunting, are not controlled by the NCWCD.

Since January 1995, $83(40: 43)$ oryx have been translocated and released. Six deaths and 23 births have been recorded. By March 1997 there were 100 wild Arabian oryx. Given the 1995 performances (fertility rate was 72.2 per cent in the females that gave birth within one year of release, mortality was 9.6 per cent, and population increase in the first year of release was nearly 30 per cent), similar recruitment in 1997 will bring the total number of oryx in the winter of $1997 / 98$ to nearly 130 individuals. A simulation model based on a 15 per cent annual increase in the population and including a fourth release planned for March/April 1998 indicates that the herd will reach 220 individuals by the year 2000. 'Uruq Bani $\mathrm{Ma}$ arid is also a reintroduction site for the sand gazelle and the mountain gazelle Gazella gazella cora.

\section{Perspectives and future challenges}

\section{Captive breeding}

The NWRC herd comprises the most diversified pool of genes for the species and maintains a high standard of health through the three-generation management programme. Although some genetic lineages are still under-represented in the herd, and substantial breeding of these founder lineages is still necessary to equilibrate the founder represen- tation, captive breeding of second generation animals has had to be reduced since June 1995 because new release sites are not yet ready for oryx. Nevertheless, the NWRC minimal viable population (population needed to conserve 90 per cent of the genetic polymorphism after 200 years) has been estimated at $250 \mathrm{~B}$-generation oryx. It is hoped to reach this number within 2 years, although maintenance of such a large herd is time consuming and expensive. New release projects in suitable protected areas as well as captive-breeding achievements are still needed. Because there is a risk of catastrophic losses in the released herds as a result of drought or unexpected disease, a core herd of oryx should be kept at the NWRC until the released populations are considered self-sustaining.

\section{Field studies}

Studies in Arabian oryx pathologies, immobilization, translocation, genetic polymorphism of the herd and reproductive physiology are ongoing (Vassart et al., 1991; Greth et al., 1992; Ancrenaz et al., 1996; Sempéré et al., 1996). As directed by the NCWCD, future research is to focus on potential management problems. Currently under study are the field ecology of reintroduced herds, the recovery dynamics of the Mahazat as-Sayd population, and the field metabolism and water requirements of Arabian oryx. These studies have as their final aims the definition of the daily energetic and water needs of Arabian oryx, and consequently may help in the estimation of oryx carrying capacities of protected areas. There is an urgent need to understand the energetic requirements of wild ungulates in order to establish livestock-grazing regulations for protected areas. Experience with Saudi Arabian protected areas has shown that total exclusion of domestic ungulates is often not feasible because it is not supported by herdsmen who consider these areas as their own.

\section{Further releases}

Survey work within the former range of the Arabian oryx was carried out in the late 1980s 
and has identified potential sites for reintroduction (Child and Grainger, 1990). Quoted in the NCWCD's Protected Area System Plan and scheduled as potential reintroduction sites are northern reserves that fall within the former distribution of the oryx: al-Khunfah, Harrat al-Harrah and at-Tubaiq (Figure 2).

Al-Khunfah $(20,450 \mathrm{sq} \mathrm{km})$ was declared by the National Board of Governors in 1988 as a multiple-use site, incorporating a Special Nature Reserve (no hunting and no livestock grazing), a Resource Use Reserve (no hunting and regulated grazing) and a Biological Reserve (preservation of a botanical seed bank). The area was ratified by the Kingdom of Saudi Arabia's Council of Ministers in 1989. It consists of an immense sand/gravel plain with low sandstone hills lying on the western edge of the Great Nafud. The area lies within the recorded northern range of the Arabian oryx and contains recognized habitat for the species. Within the Special Nature Reserve and the Resource Use Reserve daily patrols are carried out by rangers and light aircraft. The problems in the area are twofold: hunting and grazing. Despite the efforts of the patrol staff, poaching of sand gazelles is a serious problem, made worse by the accessibility of the area to vehicles and the high density of settlements surrounding the core area of the reserve. Additionally, camel grazing is affecting the distribution of gazelles and will certainly influence the success of any oryx reintroduction.

Efforts of the NCWCD to enforce the hunting ban strictly, to make the area less accessible to poachers and to regulate camel grazing will probably culminate in an oryx reintroduction in future years.

Harrat al-Harrah $(12,150 \mathrm{sq} \mathrm{km})$ was declared a Special Nature Reserve by the National Board of Governors in 1987 and was ratified by the Kingdom of Saudi Arabia's Council of Ministers in 1989. It is an undulating plain strewn with basalt boulders, volcanic ash, aeolian sand and dry lakes. Although not specifically recorded as an important area for oryx, the reserve lies within the possible range of oryx in the north-western Nafud, and may have been used at least seasonally. Hunting has been banned and tended livestock is excluded. Its remoteness and inaccessibility have facilitated the protection of wildlife in the area. Smaller than alKhunfah, the reserve is patrolled daily by rangers on the ground and in light aircraft. The reserve protects Saudi Arabia's main population of sand gazelle and possibly contains one of the last breeding populations of houbara bustard in Saudi Arabia (Seddon et al., 1995).

The principal threat to reintroduction is posed by grazing camels, sheep and goats, which could compete with oryx for food. At times over 10,000 untended camels may range freely within the reserve ( $\mathrm{T}$. Wacher, pers. comm.) and tended stocks of sheep illegally enter the area. Limitation of all grazing would certainly improve the success of a possible reintroduction project. In addition, good winter rain results in a large number of people entering the reserve to harvest the edible fungus locally known as 'fagga', Terfezia claveryi. This causes considerable disturbance to the habitat and forces the wildlife to seek refuge in quieter areas of the reserve.

At-Tubaiq $(12,200 \mathrm{sq} \mathrm{km})$ was declared a Special Nature Reserve by the National Board of Governors in 1989 and ratified by the Kingdom of Saudi Arabia's Council of Ministers in 1991. The site lies adjacent to the north-west border with Jordan. It consists of an eroded sedimentary plateau demarcated by a low escarpment from a sandy plain with gravel sheets. The area was initially selected for protection because it contains a population of Nubian ibex Capra ibex (nubiana). AtTubayq is also within the historical range of Arabian oryx. The incidence of illegal hunting of ibex is not known but assumed to be marginal. Grazing pressure of camels needs to be assessed. The feasibility of a reintroduction project still needs to be investigated.

Other protected areas (Figure 2) located in the Rub'al-Khali desert (al-Hibakah, al-'Uruq al-Mu'taridah, Shiqqat Najran) and in Great Nafud desert (Nafud al-Urayq and Jabal 'Irnan) have been identified as historically within the distribution range of the Arabian oryx and are proposed for protection. These 
sites need to be investigated and factors that might limit the sustainable re-establishment of oryx in the wild identified.

\section{Population genetics and metapopulation perspectives}

Population genetics is of major importance in the long-term management of the reintroduced herds. Oman's oryx population has demonstrated the operation of stochastic events such as male-biased sex-ratio in calves, and a low effective population size owing to to herd dynamics and sex-ratio (Stanley-Price, 1991). These events have not yet been observed in Saudi wild populations, but will express themselves in only a few years if they exist. The population genetics in 'Uruq Bani Ma'arid and Mahazat as-Sayd have been maximized through equalization of founder contribution, management of inbreeding coefficients, avoiding artificial selection, increasing the effective population size and reaching the estimated minimum viable population size as quickly as possible.

In natural conditions, deterministic and stochastic events act jointly on a population. If we consider a large population composed of several subpopulations (the future population model of the Arabian oryx in the Arabian peninsula) affected by similar factors, the systematic environmental pressures will tend to establish a stable equilibrium, and random pressures will tend to shift this equilibrium. A stable state is therefore a product of the action of systematic pressures and genetic drift. As soon as this stable state is reached, there should be a certain degree of differentiation between subpopulations, but the general distribution of the allelic frequencies will be the same as long as environmental conditions remain unchanged. The reintroduction programme for the Arabian oryx is a model of this process in reverse. Different subpopulations are being created as the base of a large oryx metapopulation in the Arabian peninsula. However, we are only at the very beginning of the process. A network of subpopulations is necessary to allow interactions and mixing between subpopulations and prevent undesirable stochastic events having an impact on isolated populations. Taking into consideration urban and agricultural development in the Kingdom of Saudi Arabia, two metapopulations could be proposed for the future.

1 An 'Empty Quarter' metapopulation comprising the subpopulation of 'Uruq Bani Ma'arid, proposed protected areas in the eastern part of the Rub'al-Khali desert and possibly connected with the White Oryx Sanctuary population in Oman.

2 A northern metapopulation, ranging in the Saudi northern protected areas network and possibly connected with the Shaumari and Talila subpopulations in Jordan and Syria.

This metapopulation strategy will prevent genetic isolation of separate populations.

\section{Threats to the species's re-establishment}

Illegal hunting. No instances of poaching of reintroduced oryx in Saudi Arabia have been documented. Nevertheless, it is probable that this threat could have significant consequences because over-hunting was the main cause of the extermination of oryx in the wild. Although hunting is regulated in Saudi Arabia and banned in protected areas, bedouin are traditionally armed, with the possession of weapons considered a vested right. Responses to enquiries made by the authors indicate that damage caused to local fauna by illegal hunting outside the protected areas can be considerable. Although the reintroduced Arabian oryx have the respect of local people, poaching of sand gazelle has shown that, despite public awareness campaigns, this threat is real. Poaching could be discouraged through active law enforcement, by giving policing powers to the rangers and allowing the confiscation of weapons. A thorough follow-up of cases through the legal system would act as a further deterrent. Finally, long-term local participation and more benefits to the local people could also help control illegal hunting. Capture. It appears that the capture of wild animals is a very old tradition in the Arab world. The Arabian oryx is easy to tame and will adapt to captivity. In the past this pre- 
vented the species being lost totally because oryx were kept in Arabian private collections as pets, and some of their descendants contributed to the creation of the World Herd. Indeed, in the early 1970 s the large captive populations in Saudi Arabia, Abu Dhabi and Qatar allowed the species to persist when oryx were already extinct in the wild. Although not recorded at present in Saudi Arabia, the threat of illegal capture has been realized for the Omani White Oryx project.

It appears that between February and November 1996 at least 40 oryx were taken from the Arabian Oryx Sanctuary (AOS). Most of these probably died of overexertion during and after capture but some were smuggled out of the country for sale to private zoos and animal collectors in the Middle East. Illegal trade in oryx may provide considerable income for animal dealers (Rowe, 1997). Although speculative, a possible solution to this problem would be to flood the market with captive-bred Arabian oryx, in order to reduce the ever-growing demand. Income from this venture would cover the cost of breeding and any excess could be donated to education programmes. However, this sudden opening up of the market could induce unexpected side-effects and lead to a very rapid increase in the poaching of other threatened wild animals.

Interspecific competition. Competition with domestic grazers is not a threat to Arabian oryx reintroduced in Mahazat as-Sayd because the reserve is fenced. However, oryx are in competition for food with other ruminants, particularly camels, in 'Uruq Bani Ma'arid. Although this competition is tolerable at the moment because the area received good rains in the springs of 1995 and 1996, and the oryx population is still small, the situation may become precarious when the wild population is large and when drought conditions prevail. It will be important to implement regulations limiting the number of domestic livestock permitted in the area, although law enforcement will be difficult when the climatic situation most necessitates it. Consistent grazing control requires a complete reform of the agri- pastoral land-use system in these areas. Ongoing research carried out at the NWRC on the energetic and water requirements of oryx in the wild may help us to determine levels at which competition can be tolerated.

Habitat degradation. In Saudi Arabia there is an intricate social structure within the tribes that range over the land masses of the Kingdom. As a consequence, non-fenced protected-area management must take into account the status and complexity of tribal social structures both inside and outside the reserve areas if the development of biological diversity and the protection of natural processes inside the reserves is to succeed. Thus, all protected areas should continue to exert socioeconomic influences on the area and its ecology (Child and Grainger, 1990). Although difficult to carry out, management of protected areas must be harmonized with outside land uses, so as to evolve strong partnerships with neighbouring resource users. Total exclusion of domestic grazers is of doubtful long-term conservation value, may not be possible to carry out and should be restricted to core areas of protected sites.

The creation of 'Uruq Bani Ma'arid protected area and release of oryx took place 35 years after the last sighting of an oryx. Although less populated than the AOS in Oman, it is likely that the habitat has also been disturbed in 'Uruq Bani Ma'arid. Further habitat degradation has been controlled by exclusion of human settlements within the core area. Wood is still a major source of energy for bedouin; the ban on tree cutting must be enforced because trees are the main source of shade for oryx during summer.

\section{Regional conservation policy}

The Sultanate of Oman was the first state in the Arabian Peninsula to progress beyond captive breeding. Oryx have been free-ranging in the AOS for more than 15 years. They have reached an estimated total number of nearly 400 animals, and are constantly monitored by trained rangers. In 1996 the first cases of poaching of oryx were recorded and demon- 
strate how difficult it is to protect totally all individuals in the long term. It is probable that Saudi Arabia will face similar problems when the number of oryx has increased to the point where it is impossible to account for all the animals daily. It is hoped that the NCWCD will be able to prevent poaching in Saudi Arabia by being ready to implement serious law enforcement.

Other Arabian oryx reintroduction projects exist within the region. In the Kingdom of Jordan, Arabian oryx have been bred in semicaptive conditions in Shaumari Wildlife Reserve for nearly 20 years (Al-Eisawi and Hattough, 1987) and the herd is now estimated at 250 individuals. While the herd was growing, staff at the Royal Society for Conservation of Nature (RSCN) expressed their concern about the future of the herd, which could not safely be contained within the restricted area of Shaumari Wildlife Reserve because of carrying capacity and disease problems. Revised management will necessitate a redefinition of the objectives of the herd towards properly scheduled conservation breeding goals. Although perhaps premature (the candidate area of Bayir batnal-Gul near the Saudi border is not yet protected and wildlife reserves are at the planning stages) reintroduction projects are already scheduled in the Jordanian Arabian oryx management plan (J. Boef, pers. comm.). One of the release areas (Wadi Bayir) is located approximately $180 \mathrm{~km}$ south-east of Amman, very close to the Saudi border. This area is close to the al-Khunfah protected area in Saudi Arabia, where a release of Arabian oryx is also planned. Because Wadi Bayir adjoins the heavily populated Wadi Sirhan in Saudi Arabia, a regional protection policy would be very helpful to ensure the success of future releases.

In autumn 1996, under the patronage of the Food and Agriculture Organisation (FAO), Syria embarked on a 'managed population' (IUCN Protected Area Category V) project in Talila reserve near Tadmoor. Eight (4:4) animals have already been acquired from Shaumari. The animals are completely dependent on the natural range for their food sup- ply; only water is provided. This operation is part of a sustainable wildlife rehabilitation project for the area. Ecotourism could become a valuable management tool for this population in the near future (D. Williamson, pers. comm.).

The Emirate of Qatar has also decided to increase the genetic polymorphism of its extremely isolated captive herd, and has requested foreign expertise. In recent years, new management problems appeared in most of the captive-breeding programmes in the Middle East, all related to overpopulation. AlAin zoo in UAE, Shahaniyah in Qatar and Shaumari in Jordan recorded deaths due to intraspecific fights and contagious disease outbreaks (i.e. foot-and-mouth disease outbreak in Shahaniyah in January and February 1997), two causes known to be related to lack of appropriate management and overstocking. Paradoxically, after facing near-extinction the Arabian oryx is now, because of a lack of suitable release sites, facing serious captive management problems in the Middle East. These could be solved by implementation in the captive-breeding sites of contraceptive controls.

It has been suggested that Saudi Arabia, as the largest country in the Arabian Peninsula, should take the lead in initiating co-operative conservation efforts between oryx range states. There is a need for regional co-operation to prevent trade, to tighten border controls and enforce CITES regulations among peninsular signatory countries. The NCWCD has already issued a draft 'Memorandum of Understanding for Cross-Border Ungulate Conservation', which could trigger regional discussion concerning wild ungulate conservation and set out multilateral agreements. Regional implementation of this policy would proceed with support from the highest governmental authorities (Figure 4).

The future aim of the NWRC breeding programme is to maintain a healthy captive population to support the wild herds and in case the wild population should collapse. We are only at the beginning of the reintroduction process, so it is difficult to assess the total number of release sites needed to ensure the long-term viability of this species. The 


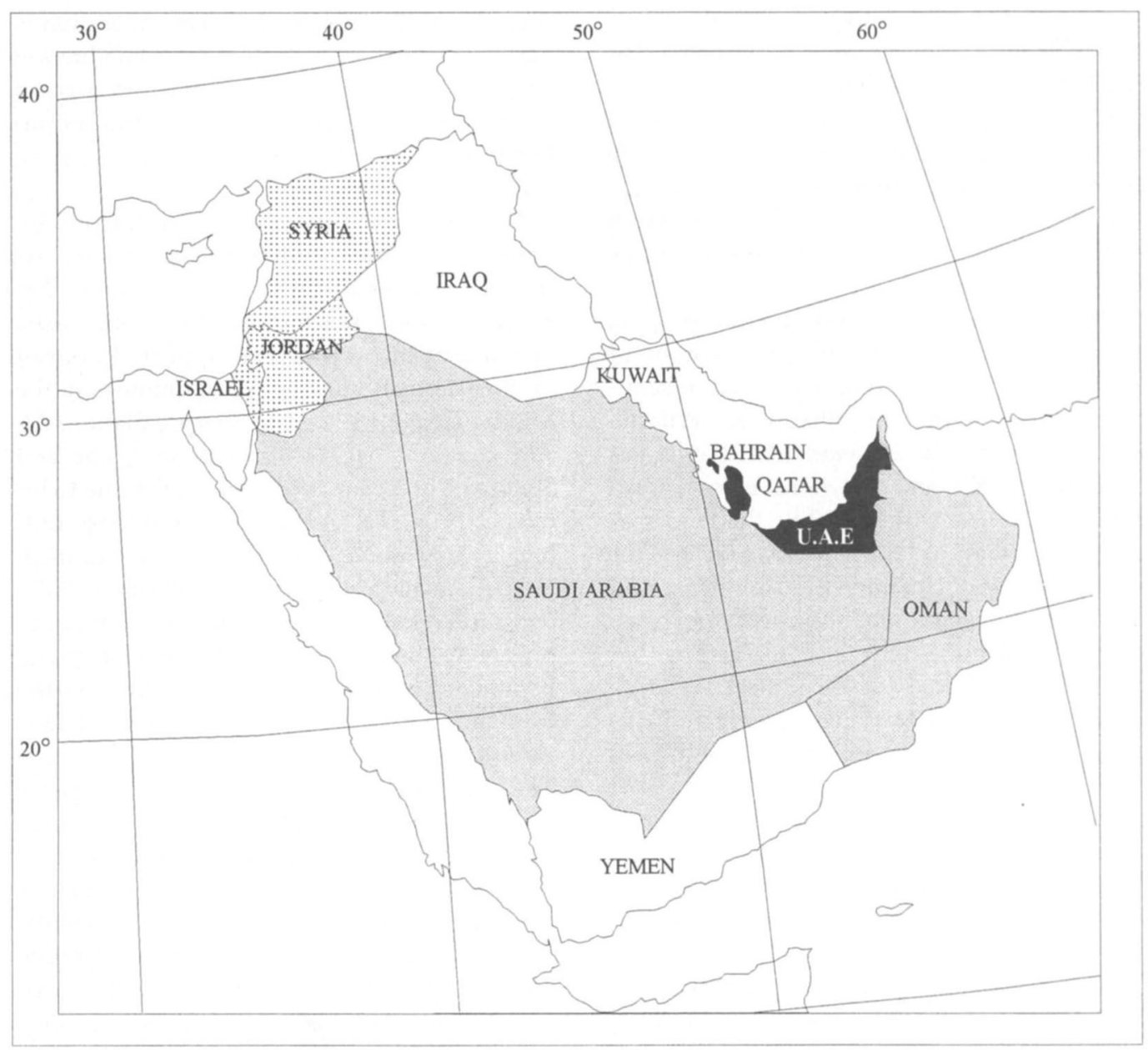

Country with reintroduced population and a captive breeding programme

Country with a managed population (IUCN Cat. V)

Country with a captive breeding programme

Figure 4. Regional strategies for Arabian oryx re-establishment in the Middle East (1997).

rehabilitation of degraded habitats and control of hunting pressures should allow other areas to become 'suitable' for oryx reintroduction. Regional co-operation in Arabian oryx reintroduction could result in the connection of population's release sites, permitting move ments between populations, i.e. between the Rub'al-Khali and the Arabian Oryx Sanctuary (Oman) and possibly between future northern release areas in Saudi Arabia and the Jordanian wildlife reserve system. The remoteness, low human population densities and lack of major economic resources in the huge Rub'al-Khali desert are factors in favour of the region receiving immediate attention. If this huge area $(630,000 \mathrm{sq} \mathrm{km})$ can be protected successfully, most of the criteria determining the long-term success of Arabian oryx reintroduction be met. The Arabian oryx population will be self-sustaining and captive herds will be no longer necessary when stable metapopulations have been successfully created. Metapopulation strategy will secure the long-term survival of the species. 


\section{Acknowledgments}

Arabian oryx conservation programmes in Saudi Arabia have been made possible through the initiatives of His Royal Highness Prince Saud Al Faisal, and under the guidance of $\mathrm{Dr}$ Abdulaziz Abuzinada, Secretary General of the NCWCD. We would also like to thank J. Renaud and A. R. Khoja, NWRC General Manager and Administrative Director, respectively. We thank Dr A. Spalton, Dr D. Williamson, Dr Y. van Heezik and Dr P. Seddon for their attentive review of the paper.

\section{References}

Abuzinada, A.H., Habibi, K. and Seitre, R. 1988. The Arabian Oryx Programme in Saudi Arabia. In Conservation and Biology of Desert Antelopes (eds A. Dixon and D. Jones), pp. 41-46. Christopher Helm, London.

Ancrenaz, M. and Flamand, J. 1995, Re-introduction of Arabian oryx and sand gazelles in the Rub $\mathrm{Al}^{\prime}$ Khali Desert, Saudi Arabia. Newsletter of the Re-introduction Specialist Group of IUCN's Species Survival Commission (SSC), 10, 10.

Ancrenaz, M., Ostrowski, S., Anagariyah, S. and Delhomme, A. 1996. Long-duration anaesthesia in Arabian oryx (Oryx leucoryx) using a Medetomidine-Etorphine combination. Journal of Zoo and Wildlife Medicine, 27 (2), 209-216.

Asmodé, J.F. and Khoja, A.R. 1988. Captive breeding of endangered species in Saudi Arabia and reintroduction projects: an overview. In Proceedings of 5 th World Conference on Breeding Endangered Species in Captivity (eds B. L. Dresser, R. W. Reele and E. J. Maruska), pp. 355-356. Cincinnati Zoo and Botanical Garden Center for Reproduction of Endangered Wildlife, Kings Island Wild Animal Habitat and the Fauna and Flora Preservation Society, Cincinnati, Ohio.

Carruthers, D. 1935. Arabian Adventure. H.F. and G. Witherby, London.

Child, G. and Grainger, J. 1990. A system for protected areas for wildlife conservation and sustainable rural development in Saudi Arabia. NCWCD, Riyadh, Saudi Arabia.

Dolan, J.M. and Sausman, K. 1992. Arabian Oryx Studbook. Zoological Society of San Diego, California, USA.

Doughty, C.M. 1888. Travels in Arabia Desert. Jonathan Cape, London.

Al-Eisawi, D. and Hattough, A. 1987. The Arabian Oryx in Jordan. Journal of Arid Environment, 14, 291-300.

Flamand, J.R.B., Greth, A., Haagsma, J. and Griffin, F. 1994. An outbreak of tuberculosis in a captive herd of Arabian oryx (Oryx leucoryx) diagnosis and monitoring. Veterinary Record, 134, 115-118

Greth, A., Calvez, D., Vassart, M. and Lefevre, P.C. 1992. Serological survey for bovine bacterial and viral pathogens in captive Arabian oryx (Oryx leucoryx). 'Office of International Epizooties' Scientific and Technical Review, 11 (4), 1163-1168.

Greth, A. and Schwede, G. 1993.The reintroduction programme for the Arabian oryx (Oryx leucoryx) in Saudi Arabia. International Zoo Yearbook, 32, 73-80.

Greth, A., Flamand, J.R.B. and Delhomme, A. 1994 An outbreak of tuberculosis in a captive herd of Arabian oryx (Oryx leucoryx): management. Veterinary Record, 134 (7), 165-167.

Grimwood, I.R. 1962. Operation Oryx. Oryx 6(6), 308-334.

Grimwood, I.R. 1988. 'Operation Oryx' the start of it all. In Conservation and Biology of Desert Antelopes (eds A. Dixon and D. Jones), pp. 1-13. Christopher Helm, London.

Haagsma, J. and Poilane, J.F. 1989. Wildlife conservation and development in Saudi Arabia. In Proceedings of the 1st Symposium on the Potential for Wildlife Conservation and Development in Saudi Arabia (ed. A. H. Abuzinada), pp. 349-357. NCWCD, Riyadh.

Hatt, R.T. 1959. The Mammals of Iraq. Miscellaneous Publications of the Museum of Zoology of the University of Michigan, No 106.

Harrison, D.L. and Bates, P.J.J. 1991. The Arabian oryx. In The Mammals of Arabia. Harrison Zoological Museum Publication. Sevenoaks, Kent, UK.

Henderson, D.S. 1974. Were they the last Arabian oryx? Oryx, 12 (3), 347-350.

Homan, W.G. 1988. The establishment of the World Herd. In Conservation and Biology of Desert Antelopes (eds A. Dixon and D. Jones), pp. 9-13. Christopher Helm, London.

Jones, D.M. 1988. The Arabian oryx in captivity with particular references to the herds of Arabia. In Conservation and Biology of Desert Antelopes (eds A. Dixon and D. Jones), pp. 47-57. Christopher Helm, London.

Nayerul Haque, M. and Smith, T. 1995. Reintroduction of Arabian sand gazelle Gazella subgutturosa marica in Saudi Arabia. Biological Conservation, 76, 203-207.

Philby, H.St.J.B. 1933. The Empty Quarter. Constable and Co., London.

Raswan, C.R. 1935. The Black Tents of Arabia. Hutchinson, London.

Rowe, A. 1997. Conservation symbol poached alive. $B B C$ Wildlife, August, 23-24.

Seddon, P.J., Saint Jalme, M., van Heezik, Y., Paillat, P., Gaucher, P. and Combreau, O. 1995. Restoration of houbara bustard populations in 
Saudi Arabia: developments and future directions. Oryx, 29 (2), 136-142.

Seddon, P.J., Ancrenaz, M., Ostrowski, S. and Magin C. 1996. Arabian oryx (Oryx leucoryx) management plan. First Draft. NCWCD, Riyadh, Saudi Arabia.

Sempéré, A.J., Ancrenaz, M., Delhomme, A., Greth, A. and Blanvillain, C. 1996. Length of oestrous cycle and gestation in the Arabian oryx (Oryx leu$\operatorname{cory} x)$ and importance of the male presence for induction of postpartum estrus. General and Comparative Endocrinology, 101, 235-241.

Shepherd, A. 1965. Flight of the Unicorn. Elek Books, London.

Smith, T. and Nayerul Haque, M. 1994. Re-introduction of red-necked ostriches in Saudi Arabia. Newsletter of the Re-introduction Specialist Group of IUCN's Species Survival Commission (SSC), 9, 5.

Stanley Price, M.R. 1989. Animal Re-introductions: the Arabian Oryx. Cambridge University Press, Cambridge.

Stanley-Price, M.R. 1991. A review of mammal re-introductions and the role of the Re-introduction
Specialist Group of IUCN/SSC. Symposium of the Zoological Society of London No. 62, 9-25.

Talbot, L.M. 1960. A look at threatened species. A report on some animals of the Middle East and southern Asia which are threatened with extermination. Oryx, 5, 153-293.

Thesiger, W. 1948. Across the Empty Quarter. Geographical Journal, 3 (1-3), 11-21.

Vassart, M., Granjon, L. and Greth, A. 1991. Genetic variability in the Arabian oryx (Oryx leucoryx). Zoo Biology, 10, 399-408.

Stéphane Ostrowski, Eric Bedin and Daniel $\mathrm{M}$. Lenain, National Wildlife Research Center, PO Box 1086, Taif, Saudi Arabia.

Abdulaziz H. Abuzinada, National Commission for Wildlife Conservation and Development, PO Box 61681, Riyadh 1157, Saudi Arabia.

Received 1 May 1997

Accepted 9 December 1997 